Rev. Interd. em Cult. e Soc. (RICS), São Luís, v. 7, n. 2, p. 241- 260, jul./dez. 2021

ISSN eletrônico: 2447-6498

\title{
Pavimentos Táteis em Paragens de Autocarro ${ }^{1}$
}

\section{Tactile Floors at Bus Stops}

MANUELA PIRES ROSA

Universidade do Algarve, Instituto Superior de Engenharia, Centro de Investigação em Turismo, Sustentabilidade e Bem-Estar (CinTurs), mmrosa@ualg.pt

GERMANA SANTIAGO DE MELLO

Universidade do Algarve

gmmello@ualg.pt

\section{RESUMO}

O Projeto de Investigação ACCES4ALL focaliza-se em interfaces modais projetadas de acordo com o conceito de "Design Universal". Tem como objetivo principal desenvolver um estudo piloto de uma paragem de autocarros acessível, inteligente e sustentável, a localizar numa interface multimodal. Num contexto de sustentabilidade social, os ambientes construídos inclusivos têm de garantir acessibilidade universal. Assim, as pessoas com deficiência visual necessitam de pavimentos táteis e/ou com diferenciação cromática que forneçam orientação e informação sobre os espaços e os meios de transporte. Com esta comunicação pretende-se apresentar exemplos internacionais de sistemas de encaminhamento, através de pavimentos táteis, em paragens de autocarro, tendo-se recorrido a pesquisa bibliográfica e realizado desenhos técnicos. Os resultados indicam que existe uma grande diversidade de soluções técnicas de encaminhamento tátil no ambiente construído, recomendando-se a necessidade de harmonização de soluções podotáteis no mundo, considerando um contexto de Turismo Acessível.

Palavras-chave: Turismo Acessível. Acessibilidade universal. Ambiente construído. Paragens de autocarro. Pavimentos táteis. Pessoas com deficiência visual.

\begin{abstract}
The ACCES4ALL research project focuses on modal interfaces designed according to the concept of "Universal Design". Its main objective is to develop a pilot study of an accessible, smart and sustainable bus stop to be located at a multimodal interface. In a context of social sustainability, inclusive built environments must guarantee universal accessibility. Thus, people with visual disability need tactile and/or chromatically differentiated pavements that provide orientation and information about spaces and means of transport. This paper intends to present international examples of guiding systems, through tactile surfaces, at bus stops, having resorted to bibliographic research and technical drawings. The results indicate that there is a great diversity of technical solutions for tactile routing in the built environment, recommending the need for harmonization of podotactile solutions in the world, considering an Accessible Tourism context.
\end{abstract}

Keywords: Accessible Tourism. Universal accessibility. Built environment. Bus stops. Tactile surfaces. People with visual disability.

\footnotetext{
${ }^{1}$ Artigo submetido para avaliação em 17 de setembro de 2021 e aprovado em 17 de novembro em 2021.
} 
Rev. Interd. em Cult. e Soc. (RICS), São Luís, v. 7, n. 2, p. 241- 260, ago./dez. 2021

ISSN eletrônico: 2447-6498

\section{INTRODUÇÃO}

O Projeto de Investigação Científica e Desenvolvimento Tecnológico ACCES4ALL - Acessibilidade para Todos no Turismo focaliza-se em interfaces modais projetadas de acordo com os conceitos de "Design Universal" e de "Age Sensitive Design". Tem como objetivo principal desenvolver um estudo piloto de uma paragem de autocarros acessível, inteligente e sustentável, a localizar no Aeroporto Internacional de Faro.

O Turismo Acessível requer que se considere o Design Universal permitindo que pessoas com requisitos de acesso (problemas motores, visão, audição e dimensões cognitivas), funcionem independentemente e com equidade e dignidade através da existência de produtos, serviços e ambientes turísticos de conceção universal (Darcy \& Dickson, 2009). Esta definição inclui todas as pessoas, incluindo as que viajam com crianças em carrinhos de bebé, pessoas com deficiência, turistas com trolleys e pessoas idosas.

A acessibilidade universal deve ser atendida em toda a cadeia de valor do turismo onde se inserem os ambientes construídos e todos os elementos dos sistemas de transporte. Em consequência, os veículos de transporte coletivo (aéreo, marítimo, fluvial, ferroviário e rodoviário) e as zonas de interface modal (pedestre/transportes coletivos, transporte coletivo/ transporte coletivo, pedestre/automóvel) devem ser projetados de forma a garantir um uso equitativo por parte das pessoas com diversidade funcional e das demais pessoas com mobilidade reduzida.

As interfaces modais constituem um dos elementos fundamentais da rede de transportes e devem garantir acessibilidade dos passageiros aos meios de transporte, sendo então necessário integrá-las no espaço urbano e, consequentemente, na rede pedonal.

Assim, as zonas de interface modal devem ser acessíveis de forma a garantir condições de autonomia para todos os peões satisfazerem as suas necessidades de deslocação. Para tal ser possível é necessário dotar estes espaços de recursos adequados que permitam o movimento de todos. Para o caso específico das pessoas com deficiência visual, constata-se que esta acessibilidade é quebrada pela inexistência de pavimentos táteis e/ou com diferenciação cromática que forneçam orientação e informação a estes utilizadores do sistema de transporte.

Os pisos táteis são superfícies texturizadas e de cores contrastantes, perceptíveis e identificáveis ao toque com os pés ou com a bengala branca ou através de visão funcional residual. São utilizados para orientar e informar as pessoas com deficiência visual sobre determinada situação que requer atenção. 
Rev. Interd. em Cult. e Soc. (RICS), São Luís, v. 7, n. 2, p. 241- 260, ago./dez. 2021 ISSN eletrônico: 2447-6498

A tipologia de paragem de autocarro está dependente do sistema mecânico de acesso ao interior do veículo que garante a sua acessibilidade universal: a) o veículo tem uma plataforma elevatória para utilização por parte, por exemplo, de uma pessoa em cadeira de rodas; b) o veículo tem piso rebaixado e sistema kneeling ("ajoelhamento") - o que permite a utilização de uma rampa suave para garantir autonomia e segurança por parte das pessoas com mobilidade reduzida; c) o veículo tem piso rebaixado mas não tem sistema kneeling - o que requer que as plataformas de espera sejam sobrelevadas para garantir uma inclinação suave da rampa de acesso.

Neste contexto, há que garantir que as diferentes tipologias de paragens de autocarro ofereçam condições de conforto, segurança e informação favoráveis a uma maior utilização do transporte coletivo por parte das pessoas com deficiência visual. O tipo de interface modal, enquadrado nesta comunicação, é o de pedestre-transporte coletivo (autocarro), vulgarmente designada por "paragem de autocarro", considera um veículo com $12 \mathrm{~m}$ de comprimento e duas portas e uma área de embarque.

Com este artigo pretendem-se apresentar exemplos internacionais de sistemas de encaminhamento através de pavimentos táteis de paragens de autocarro, tendo-se recorrido a uma pesquisa bibliográfica. A análise foi focalizada nos países emissores de turistas para o Aeroporto Internacional de Faro (Reino Unido, Alemanha, Espanha, França, Bélgica, Brasil) e no Dubai, por este país ter uma das mais completas e recentes normas de Design Universal que existem internacionalmente (GOVERNMENT OF DUBAI, 2017). Assim, consolidam-se as informações coletadas em diferentes instrumentos, tais como leis, decretos, normas, manuais e guias técnicos, elaborados por diferentes instituições e atores.

A investigação tem por objetivo dar orientações para a utilização de pisos táteis e/ou com diferenciação cromática em paragens de autocarro, considerando as situações específicas: a) identificação da paragem de autocarro; b) identificação do local de embarque; c) marcação do rebordo do lancil; d) situações em que se utilizam somente faixas com diferenciação cromática. Estas tipologias de composição de piso tátil são geralmente associadas entre si para melhor comunicar às pessoas com dificuldades visuais informações relevantes numa paragem de autocarro.

\section{A EMERGÊNCIA DA MOBILIDADE INCLUSIVA}

A temática da mobilidade inclusiva tem vindo a ser discutida há décadas num contexto institucional. De acordo com Gallez \& Motte-Baumvol (2017), o conceito de 
Rev. Interd. em Cult. e Soc. (RICS), São Luís, v. 7, n. 2, p. 241- 260, ago./dez. 2021

ISSN eletrônico: 2447-6498

"mobilidade inclusiva" surge inicialmente na França e depois no Reino Unido, associados ao problema da exclusão social. Na França, a questão do "direito ao transporte" foi colocada na Lei das diretrizes de transporte terrestre de 1982 (Loi d'orientation sur les transports intérieurs). O reconhecimento da ligação entre exclusão social e mobilidade veio no Reino Unido, em 1998, com o Livro Branco sobre os transportes, intitulado "A new deal for transport: better for everyone". A prioridade foi promover a implementação de uma política integrada de transportes de forma que contribuisse para uma política mais justa e inclusiva.

A Organização das Nações Unidas emitiu a Declaração dos Direitos das Pessoas com Deficiência em dezembro de 1975, tendo-se desencadeado dinâmicas em todos os sectores públicos. As conferências internacionais sobre mobilidade e transporte de pessoas idosas e pessoas com deficiência (International Conference on Mobility and Transport for Elderly and Disabled People) desenvolvidas desde 1978, por instituições americanas, constituíram uma referência padrão para investigadores, planeadores e operadores de transportes.

Na União Europeia, a temática da inclusão social tem vindo a ser progressivamente integrada nas políticas de transportes por influência do trabalho desenvolvido pelas diversas instituições europeias. A 2 de Dezembro de 1992, a Comissão Europeia adotou a Comunicação "Futura Evolução da Política Comum de Transportes", onde apresentou uma abordagem inovadora da Política Comum de Transportes ao considerar os objetivos de proteção do ambiente e de reforço da coesão económica e social, visando a construção de um quadro comunitário que garantisse uma mobilidade sustentável. Na linha de ação referente à proteção social fazia referência à melhoria do transporte para as pessoas com mobilidade reduzida e, portanto, a melhoria das condições de acessibilidade para todos na componente dos transportes.

Neste âmbito, em 2001, foi aprovada a Diretiva Europeia 2001/85/CE relativa a disposições especiais aplicáveis aos veículos destinados ao transporte de passageiros com mais de oito lugares sentados além do condutor que visava melhorar as condições de acessibilidade dos autocarros urbanos da União Europeia, permitindo o acesso das pessoas com mobilidade reduzida.

Esta diretiva teve como suporte as recomendações do relatório COST 322 (1995). De acordo com este, consegue-se um fácil acesso para todos os usuários através de um autocarro de piso rebaixado. Ocorre somente um simples degrau no embarque de cerca $32 \mathrm{~cm}$ desde o pavimento da faixa de rodagem. Se existir um mecanismo de kneeling reduz o desnível para somente $25 \mathrm{~cm}$. Neste caso, considerando a paragem de autocarro, é possível sobre-elevar o lancil de 16 a $18 \mathrm{~cm}$ e conseguir sensivelmente o mesmo nível de acesso. Esta situação 
Rev. Interd. em Cult. e Soc. (RICS), São Luís, v. 7, n. 2, p. 241- 260, ago./dez. 2021

ISSN eletrônico: 2447-6498

associada a uma rampa no veículo faz com que uma pessoa em cadeira de rodas possa facilmente embarcar sem ajuda acrescida.

Em 2011, é publicado o Regulamento n. ${ }^{\circ}$ 181/2011 do Parlamento Europeu e do Conselho respeitante aos direitos dos passageiros no transporte de autocarro, incluindo os passageiros com deficiência.

A Convenção sobre os Direitos das Pessoas com Deficiência, adotada em Nova Iorque no dia 13 de dezembro de 2006, adotou o modelo social/ecológico do funcionamento humano, assumindo que a incapacidade está intrinsecamente relacionada com a interação entre as características das pessoas e as barreiras comportamentais e/ou ambientais que existem na sociedade e que interferem na sua inclusão e participação.

Esta ênfase nos fatores ambientais determina que o meio edificado, os sistemas de transporte e de comunicação e os serviços têm de ser concebidos considerando o conceito de "equidade social" que está associado a valores de justiça e solidariedade, à igualdade de oportunidades no acesso a bens, serviços e informação e a formas alternativas de comunicação. Este conceito aplica-se à atividade de transporte e deve ser considerado em toda a cadeia do sistema de transportes.

Em consenso com o referido, a Estratégia Europeia para a Deficiência 2010-2020 apresenta o conceito de "acessibilidade" que significa que as pessoas com deficiência têm acesso, em condições de igualdade com os demais cidadãos, ao ambiente construído, aos transportes, aos sistemas e tecnologias da informação e comunicação e a outras instalações e serviços. Um serviço de autocarro totalmente acessível é um elemento essencial na garantia de uma sociedade plenamente inclusiva (TRANSPORT FOR LONDON, 2006).

As paragens de autocarro acessíveis são um elo vital numa mobilidade inclusiva pelo que têm de ser concebidas para atender às necessidades específicas das pessoas com incapacidade sensorial, intelectual ou física.

\section{TIPOLOGIAS DE PISOS TÁTEIS}

Os documentos dos países pesquisados apresentam soluções bastante diversas, apesar de utilizarem para isso elementos indicadores e linguagens semelhantes. Os elementos indicadores geralmente utilizados, são o piso nervurado, o piso de alerta (botão) e o piso liso/macio (Quadro 1). 
Rev. Interd. em Cult. e Soc. (RICS), São Luís, v. 7, n. 2, p. 241- 260, ago./dez. 2021

ISSN eletrônico: 2447-6498

O piso nervurado tem um relevo linear, com elevações salientes (nervuras), paralelas entre si, geralmente planas, cujas arestas e extremidades podem ser retas ou levemente arredondadas, e cujos espaçamentos podem ser regulares ou não.

Quadro 1: Tipologias e funções de pisos táteis

\begin{tabular}{|c|c|c|c|c|}
\hline Tipologia & \multicolumn{2}{|c|}{ Piso nervurado } & Piso de botão & Piso liso/macio \\
\hline Função & $\begin{array}{c}\text { Direção } \\
\text { (se longitudinal) }\end{array}$ & $\begin{array}{l}\text { Atenção/cautela } \\
\text { (se transversal) }\end{array}$ & $\begin{array}{l}\text { Alerta/ atenção/ } \\
\text { vigilância }\end{array}$ & $\begin{array}{l}\text { Informaçãão, } \\
\text { indicação, } \\
\text { contraste }\end{array}$ \\
\hline Desenho & & $\begin{array}{l}\square \\
\\
\\
\\
\end{array}$ & $\begin{array}{llllll}0 & 0 & 0 & 0 & 0 & 0 \\
0 & 0 & 0 & 0 & 0 & 0 \\
0 & 0 & 0 & 0 & 0 & 0 \\
0 & 0 & 0 & 0 & 0 & 0 \\
0 & 0 & 0 & 0 & 0 & 0 \\
0 & 0 & 0 & 0 & 0 & 0\end{array}$ & \\
\hline
\end{tabular}

Fonte: Elaboração própria

De acordo com a forma de aplicação - se longitudinal ou transversal à marcha - o tipo de piso assume diferentes propósitos e comunica diferentes informações.

Quando o piso nervurado é aplicado longitudinalmente, geralmente assume a função de direção/condução, guia, orientação, sendo utilizada para indicar caminhos, rotas, percursos. Em Portugal, a ACAPO recomenda que sejam aplicados em poucas circunstâncias na via pública, basta que seja respeitado, rigorosamente, o conceito de canal de circulação contínuo e desimpedido de obstruções (percurso acessível) que consta no Decreto-lei 163/2006 de 8 de agosto. Em Espanha, a sua utilização é recomendada na ausência de linha de fachada. Já na Bélgica, quando uma situação pode levar a desorientação.

Quando o piso nervurado é aplicado transversalmente, geralmente assume a função de indicação, advertência, cautela, perigo, sendo utilizado para indicar mudança de direção, pontos de interesse (paragem de autocarro, ponto de informação, pontos de travessias), mudança de nível (escadas e rampas), passagem de nível ou aproximação de desnível em plataformas em estações de comboio (perigo). Quando utilizado para recomendar atenção/cautela, o piso apresenta um maior número de nervuras com menores espaçamentos entre si.

O piso de alerta tem um perfil de relevo "pitonado" (botão), composto por cúpulas salientes (arredondadas) de topo plano, de espaçamentos geralmente regulares e altura suficiente para ser detectável ao toque com os pés (4 a $5 \mathrm{~mm}$ ). O padrão de distribuição dos relevos no piso pode ser escalonado ou retilíneo, não tendo sido observada, no entanto, uma 
Rev. Interd. em Cult. e Soc. (RICS), São Luís, v. 7, n. 2, p. 241- 260, ago./dez. 2021 ISSN eletrônico: 2447-6498

regra na utilização de um ou outro tipo de piso, nos países pesquisados. Pode ser utilizado para indicar mudança de direção, presença de obstáculos, mudança de nível (escadas e rampas), pontos de travessia pedonal, aproximação de desnível em plataformas (perigo). Em alguns casos o posicionamento do piso pitonado pode indicar a direção da marcha.

O piso liso/macio tem um perfil liso, sem relevo. Adota diferentes características de país para país, sendo identificadas sobretudo diferenças de rigidez/flexibilidade e de cor. Pode ser utilizado para indicar mudança de direção, presença de um equipamento, presença de informação ou, como ocorre na Alemanha, para reforçar o contraste tátil-visual entre o piso tátil, nervurado e de botão, e o piso adjacente.

\section{EXEMPLOS INTERNACIONAIS DE PAVIMENTOS TÁTEIS EM PARAGENS DE AUTOCARRO}

\subsection{Reino Unido}

O Departamento dos Transportes desenvolveu recomendações para a conceção de paragens de autocarros acessíveis (Department for Transport, 2002). Recomenda a não utilização de pisos táteis nas paragens e plataformas elevadas, uma vez que a existência de uma sinalização deste tipo pode induzir a pessoa com deficiência visual ao erro e provocar acidentes.

Existe um guia específico sobre a utilizaçãpo de pavimentos táteis que define o âmbito, aplicação, manutenção e desenho de sete diferentes tipos de pavimentos tácteis e fornece orientação sobre quais cores devem ser usadas onde (Department for Transport, 2007). Para chamar a atenção para instalações pode-se recorrer a uma superfície de informação, que não tem relevo, mas é feita de um material que é, ligeiramente, mais macio do que os materiais de pavimentação convencionais, por exemplo, borracha de neoprene (Figura 1) ou composto elastomérico similar. Esta superfície de informação emborrachada é usada para destacar os elementos principais do mobiliário urbano que existem em ambientes pedestres, como caixas de telefone e caixas de multibanco, que as pessoas com deficiência visual podem ter dificuldade em localizar. Este novo material deve contrastar em cor e textura com a área circundante.

$\mathrm{Na}$ plataforma de espera deve fornecer-se uma faixa lisa e macia (linha amarela de $10 \mathrm{~cm}$ ), paralela e afastada em $45 \mathrm{~cm}$ do lancil, para fornecer orientação aos motoristas de autocarro e indicar aos passageiros que devem ficar longe da borda da plataforma. 
Rev. Interd. em Cult. e Soc. (RICS), São Luís, v. 7, n. 2, p. 241- 260, ago./dez. 2021 ISSN eletrônico: 2447-6498

Figura 1: Exemplo de localização de uma superfície de informação

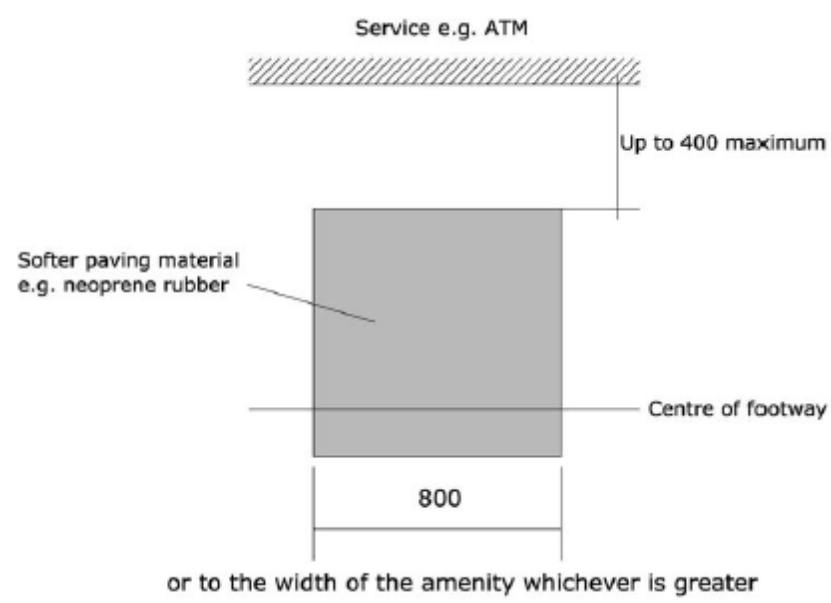

Fonte: Transport Scotland $(2013,30)$

Howard et al. (2015) referem a necessidade de uma revisão das orientações sobre a pavimentação tátil, que dão sobretudo ênfase à detetabilidade e/ou contraste cromático e que há necessidade de minimizar os efeitos das rampas de rebaixamento do lancil em travessias pedonais pois originam quedas por parte dos idosos.

Na plataforma de espera de uma paragem de autocarro, pode haver uma faixa de advertência, paralela ao lancil, através de marcas de superfície (Figura 2). Usualmente, são usados pavimentos com um bom contraste de cores com a pavimentação circundante, pois a pavimentação tátil pode ser desconfortável para algumas pessoas idosas (Ormerod et al., 2015).

\subsection{Alemanha}

$\mathrm{Na}$ Alemanha, a tipologia Auffindestreifen $(A F)$, ou faixa direcional ou de localização, é utilizada em qualquer contexto em que se pretendam indicar pontos de interesse laterais ou o próprio percurso.

Figura 2: Pavimentos com contraste cromático numa paragem de autocarros no Reino Unido

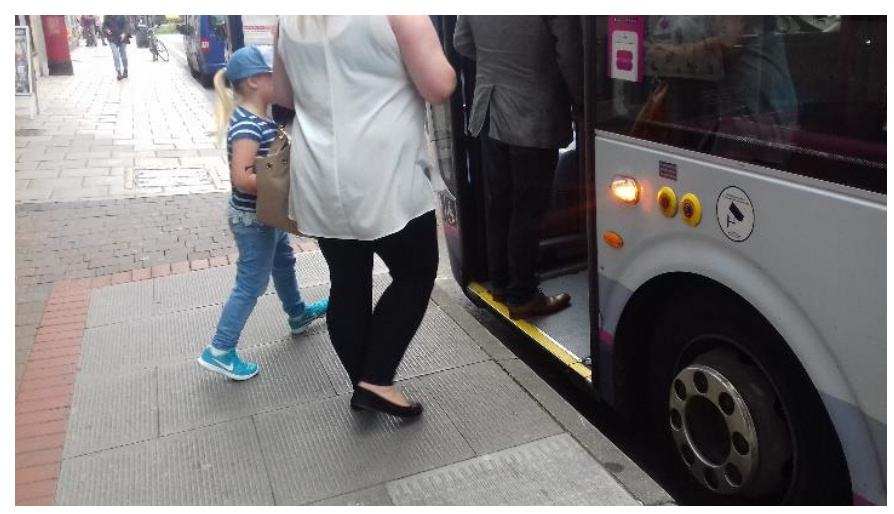


Rev. Interd. em Cult. e Soc. (RICS), São Luís, v. 7, n. 2, p. 241- 260, ago./dez. 2021

ISSN eletrônico: 2447-6498

\section{Fonte: Ficheiro pessoal}

Assim sendo, essa tipologia pode ser utilizada para comunicar a presença de uma paragem de autocarro, em associação com outra tipologia, o Einstiegsfeld (EF), ou "ponto de entrada", que exerce a função de indicação do local de embarque na paragem de autocarro. Este é identificado através de placas nervuradas, colocadas paralelas ao lancil, que indicam o ponto de espera para embarque direto na porta dianteira dos autocarros ou elétricos. Este local de embarque pode ser identificado no final da faixa direcional e ter uma extensão de cerca de 0,60 m (DBSV, 2016).

Na Figura 3 mostram-se exemplos de aplicação de piso tátil numa paragem de autocarro na Alemanha, podendo-se visualizar a utilização de pavimentos com diferenciação cromática, na envolvência do piso tátil.

Figura 3: Exemplos de aplicação de piso tátil numa paragem de autocarro na Alemanha

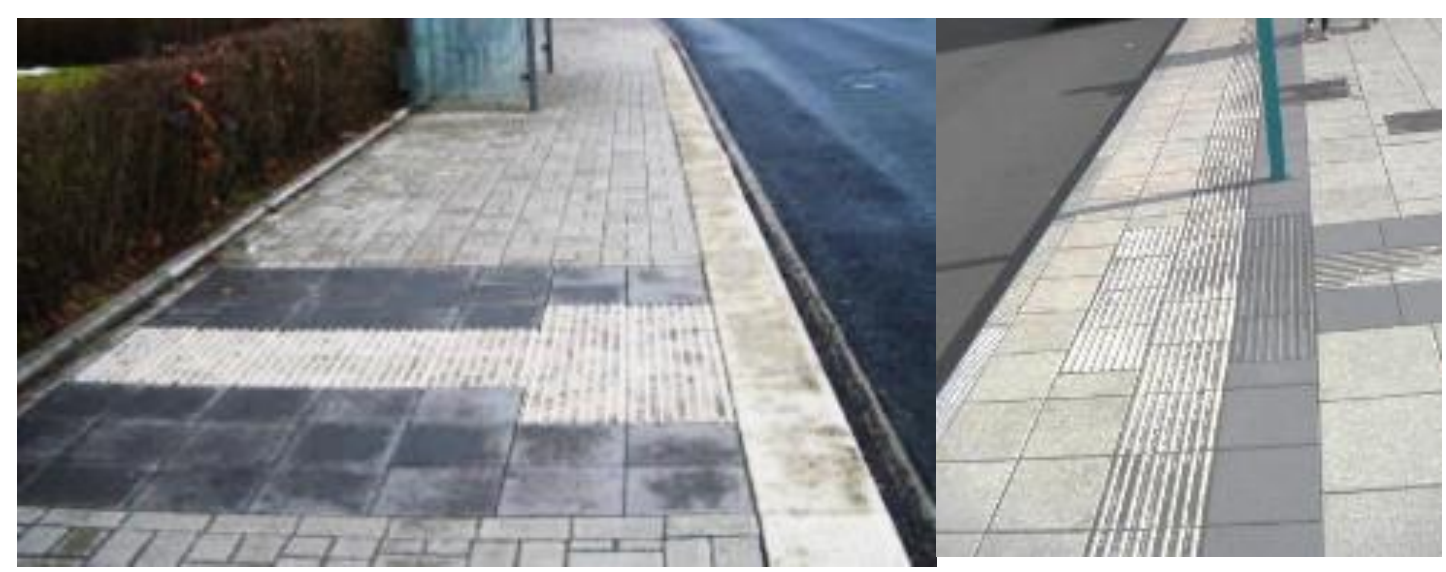

Fonte: Kohaupt (2014, p. 05)

\subsection{Espanha}

Em Espanha, a presença das paragens é sinalizada, no passeio, por meio da colocação de uma faixa tátil, de deteção tato-visual, com $120 \mathrm{~cm}$ de largura e com grande 
Rev. Interd. em Cult. e Soc. (RICS), São Luís, v. 7, n. 2, p. 241- 260, ago./dez. 2021 ISSN eletrônico: 2447-6498

contraste cromático em relação às áreas adjacentes do pavimento. Esta faixa será executada transversalmente à marcha, ao longo de toda a largura do passeio, da fachada do edifício, área ajardinada ou parte mais externa do percurso dos pedestres, até ao lancil (meio-fio) (Figura 4).

A faixa de orientação dista pelo menos $0,40 \mathrm{~m}$ da linha da fachada e prolonga-se até a uma distância de 0,90 m do lancil. Nesse espaço de 0,90 m, está situada, a uma distância de 0,40 m, da tipologia anterior, a faixa de advertência (franja de advertencia de peligro de los andenes), que consiste numa linha de blocos de atenção (botão), paralela e próxima ao lancil, de cor amarela, refletora e brilhante, e cuja largura é, idealmente, de 0,50 m (mínimo absoluto de 0,40 m). Esta faixa adverte para desnível de plataformas (comboio, autocarro) e tem comprimento variável em função da dimensão da paragem. Também o comprimento da faixa de identificação da paragem de autocarro varia em função da largura do passeio. Observa-se ainda o contraste cromático em relação às áreas adjacentes do pavimento.

Figura 4: Pisos táteis direcionais em paragens de autocarros em Espanha
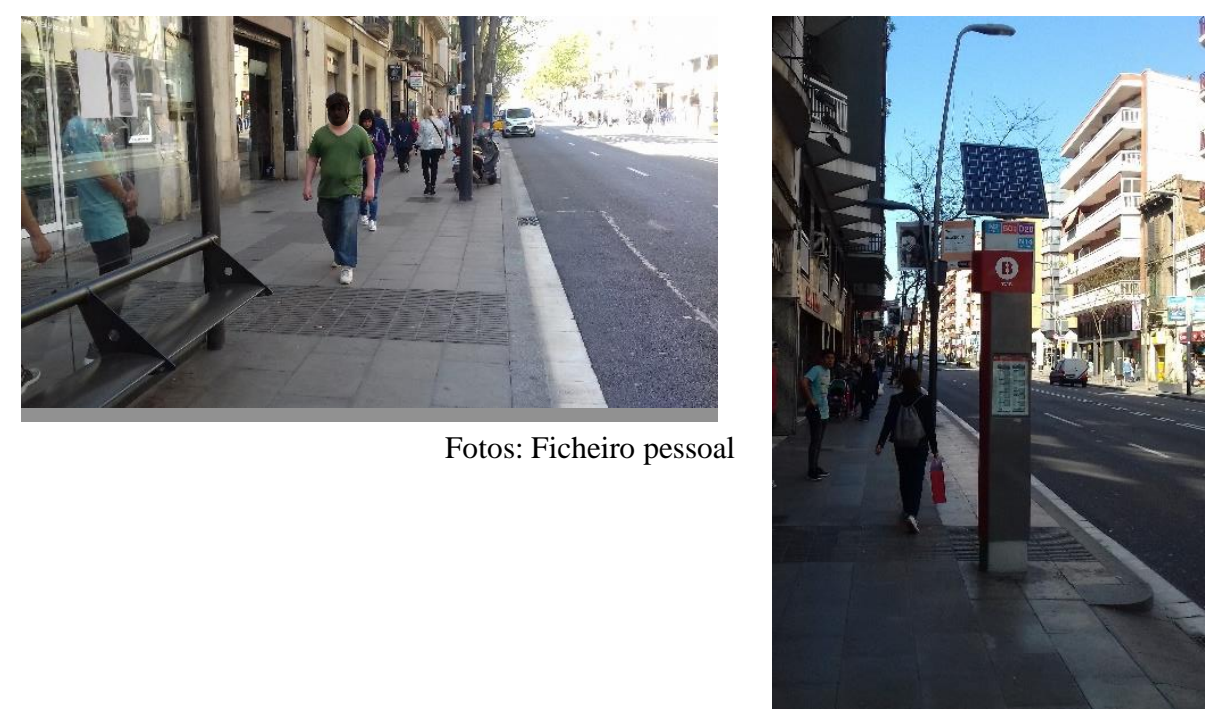

\subsection{Bélgica}

$\mathrm{Na}$ Valónia a sinalização horizontal de identificação do local de embarque, para todos os tipos de paragens de autocarro, é colocada no eixo da porta dianteira do autocarro, indicando assim o ponto de acesso ao veículo (GAMAH, 2006).

Corresponde a um bloco quadrado de um piso liso/macio, de 0,60 x 0,60 m, situado a uma distância de 0,30 a 0,60 m do lancil, complementado por uma faixa de lajes nervuradas de 0,60 m de largura que cortam o trajeto lógico do pedestre, colocadas em toda a largura do passeio, desde a fachada dos edifícios, até ao piso liso/macio (Figura 5). 
Rev. Interd. em Cult. e Soc. (RICS), São Luís, v. 7, n. 2, p. 241- 260, ago./dez. 2021 ISSN eletrônico: 2447-6498

Figura 5: Esquema de uma paragem de autocarro integrada num passeio na Bélgica

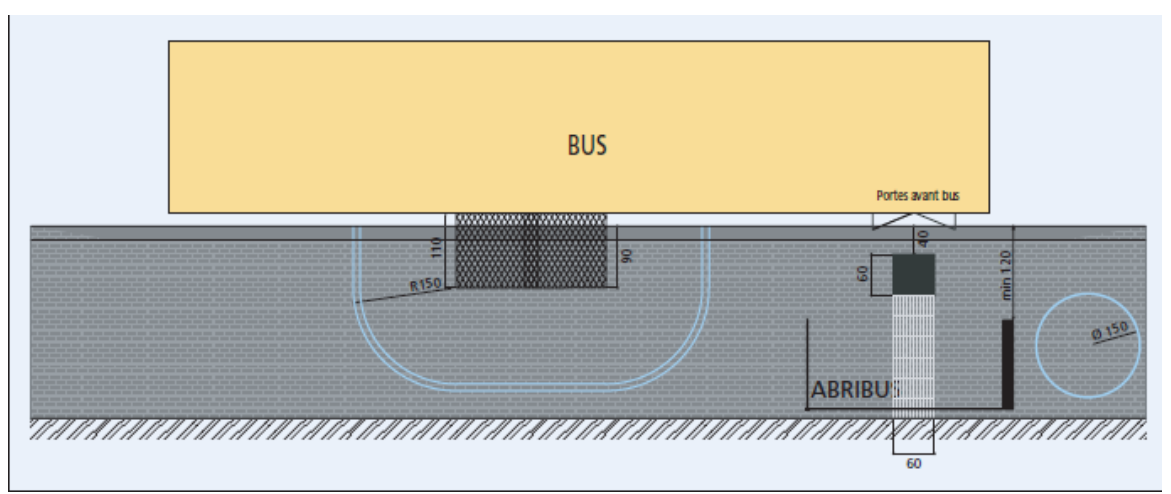

Fonte: GAMAH (2006, fiche 4.1)

\subsection{França}

No caso da França, a regulamentação impõe instalações que garantam acessibilidade, devendo ser pensada a partir de uma perspetiva de design universal. O deslocamento de pessoas com deficiência visual deve ser assegurado, assumindo-se soluções auditivas, táteis ou arquitetónicas confiáveis (CEREMA, 2014).

Numa paragem de autocarro o viajante deficiência visual deve conseguir identificar a posição da porta da frente do veículo, de modo a estar perto para ouvir o anúncio da indicação de linha e destino (que equipa a frota de veículos) e consiga estar em contato verbal com o motorista (CERTU, 2010).

Existe uma grande diversidade de documentos sobre acessibilidade universal em paragens de autocarro. Numa das soluções encontradas, o comprimento da faixa de identificação da paragem de autocarro varia em função da distância entre o lancil e o mobiliário urbano (SMT, 2009). Nesse caso, a faixa tem início a uma distância de 0,60 m a partir do mobiliário ou fachada e segue até à Bande Contrastée, marcação contrastante do rebordo do lancil, situada a $0,50 \mathrm{~m}$ do lancil, em frente à porta dianteira do autocarro.

Utiliza-se uma faixa contrastante de $0,50 \mathrm{~m}$ de largura em todo o comprimento da plataforma para, em situações de plataforma de espera sobreelevada, sinalizar a proximidade do lancil para alertar as pessoas cegas e de baixa visão (Figura 5). Recomenda-se, igualmente, a existência de uma faixa com contraste visual (idealmente branco sobre preto) com 0,60 $\mathrm{m}$ de largura entre o mobiliário urbano/fachada e a porta da frente do autocarro. A porta central do autocarro pode ser sinalizada por um pavimento com contraste visual com um quadrado branco (idealmente branco sobre preto) e um logotipo de pessoa com cadeira de rodas 
Rev. Interd. em Cult. e Soc. (RICS), São Luís, v. 7, n. 2, p. 241- 260, ago./dez. 2021 ISSN eletrônico: 2447-6498

(símbolo internacional de acesso). Este último pavimento também serve como uma marca de paragem para orientar o motorista a posicionar veículo.

A norma francesa NF P98-351 enquadra a utilização de bande d'éveil de vigilance $B E V$ (faixa tátil). Nesta norma não se recomenda o uso de piso tátil em paragens de autocarro. Considera-se que estas faixas devem ser reservadas para plataformas com altura superior a 0,26 m para transporte guiado (ferroviário) e travessias pedonais. Colocá-los numa paragem de autocarro pode induzir em erro as pessoas cegas e de baixa visão, ao fazerem confusão com uma travessia pedonal, colocando-as em risco de queda.

Figura 6: Sinalização horizontal em paragem de autocarro em França

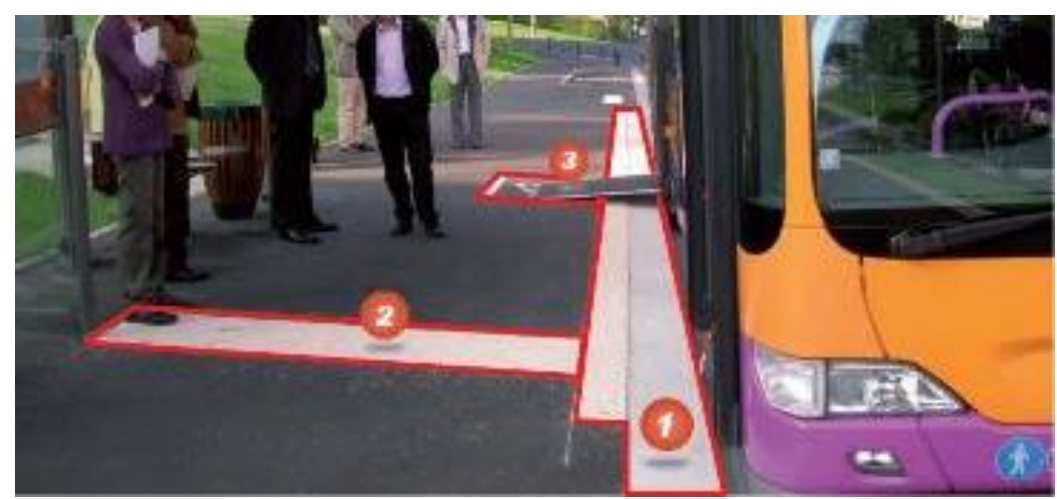

(1) Faixa com $0,50 \mathrm{~m}$ de contraste visual limítrofe ao lancil em todo o comprimento da plataforma de espera (2) Faixa com 0,60 m de contraste visual para sinalizar a porta de embarque do autocarro

(3) Faixa de contraste visual para sinalizar a porta central do autocarro

Fonte: Adaptado de SMT $(2009,13)$

\subsection{Brasil}

No Brasil, a localização da paragem de autocarro é feita a partir da colocação de um piso tátil direcional (nervurado) de $0,60 \mathrm{~m}$ de largura e comprimento variável, transversalmente ao passeio, que intercepta a marcha do pedestre e o conduz ao local de embarque, em frente à porta dianteira do veículo (ABNT NBR 9050, 2004).

A identificação do local de embarque, por sua vez, consiste numa sinalização tátil direcional (nervurada) junto à marcação tátil do rebordo do lancil, localizada na zona da porta dianteira do veículo. Suas dimensões variam entre $0,75 \mathrm{~m}$ x 0,75 m (ou 1,00 m x 1,00 m), e o seu afastamento do lancil varia em função da largura da marcação do rebordo do lancil.

Esta solução, no entanto, não deve ser utilizada em plataformas de espera elevadas. Nesses casos, utiliza-se uma "linha de retenção", correspondente à marcação tátil do rebordo do lancil, afastada a 0,50 m deste, para indicação prévia de desnível em plataforma elevada (Figura 5). Consiste numa faixa de sinalização de piso tátil de alerta (botão), de 0,40 a 0,60 m 
Rev. Interd. em Cult. e Soc. (RICS), São Luís, v. 7, n. 2, p. 241- 260, ago./dez. 2021 ISSN eletrônico: 2447-6498

de largura, paralela ao lancil, a $0,50 \mathrm{~m}$ do bordo, instalada em toda a extensão, de forma contínua, onde houver risco de queda. Esta faixa contínua coincide ainda com a sinalização de base ou topo das rampas de acesso, a pelo menos $0,50 \mathrm{~m}$ do início da mudança de nível (Figura 5).

7: Piso tátil em paragem de autocarro com plataforma sobreelevada no Brasil

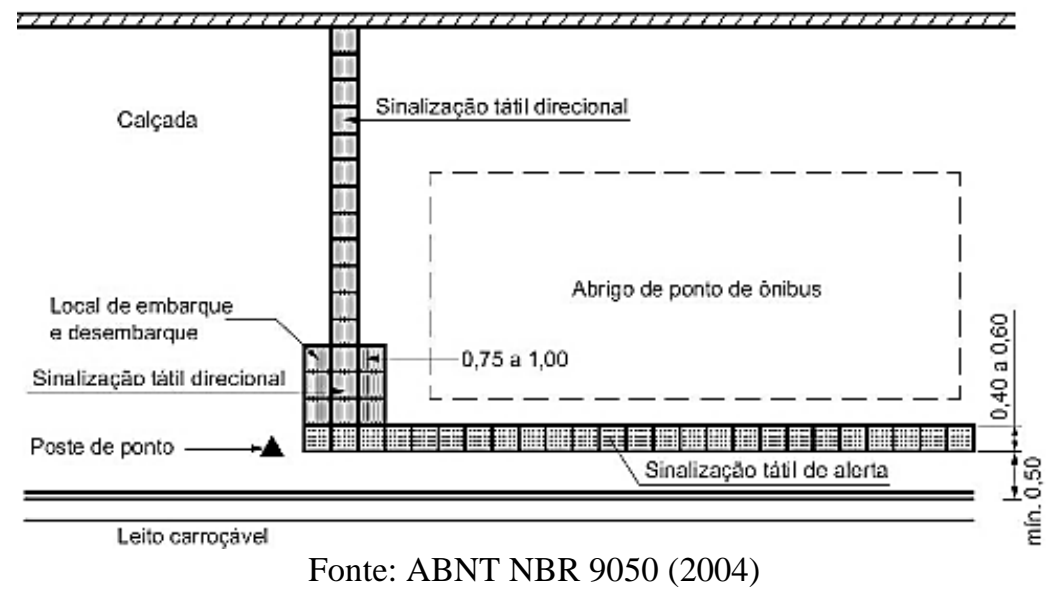

\section{Figura 8: Sinalização tátil de alerta junto a desnível em plataforma de embarque e desembarque no Brasil}

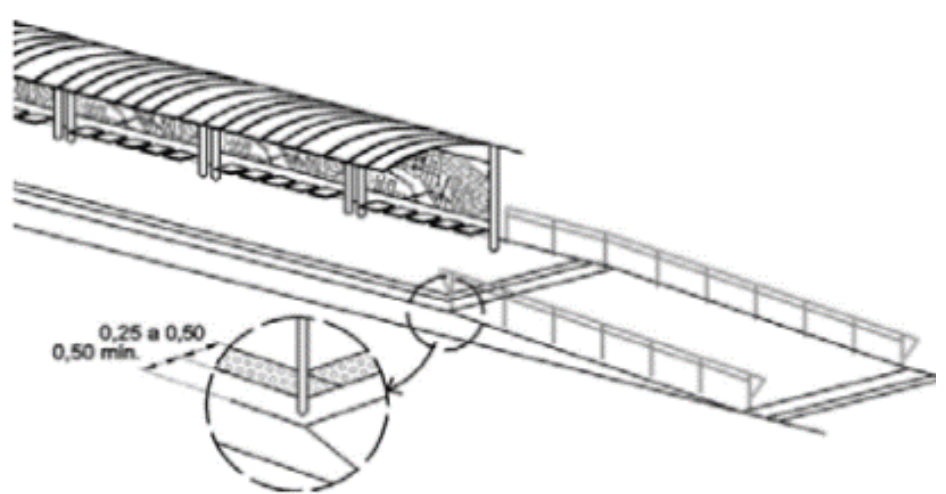

Fonte: ABNT NBR 9050 (2004)

\subsection{Dubai}

O documento Dubai Universal Design Code (Government of Dubai, 2017) é o documento de referência para o design universal em ambientes construídos públicos e privados no Dubai. Reconhece que o recurso à orientação táctil é muito útil para pessoas 
Rev. Interd. em Cult. e Soc. (RICS), São Luís, v. 7, n. 2, p. 241- 260, ago./dez. 2021 ISSN eletrônico: $2447-6498$

cegas ou com baixa visão, que utilizam a bengala branca. A orientação também se consegue fazer através de paredes, fachadas, portas ou de mudanças de textura em pavimentos.

Nas paragens de autocarro, o pavimento tátil é utilizado unicamente para identificar o local de embarque. Recomenda-se a colocação de uma faixa de aviso de cor de alto contraste de refletância com o pavimento envolvente (diferença de pelo menos 50 pontos em valor de reflexão da luz), para que seja melhor identificada por pessoas cegas ou com baixa visão. $\mathrm{O}$ piso deve ser instalado paralelamente, distanciado pelo menos de $0,30 \mathrm{~m}$ da borda do lancil, no local correspondente à porta dianteira do veículo quando este estiver estacionado próximo à plataforma de embarque (Figura 5). A superfície de aviso deve ter uma largura entre 0,30 m e $0,40 \mathrm{~m}$ e a altura não superior a $4 \mathrm{~mm}$.

Figura 9: Piso tátil em paragem de autocarro no Dubai

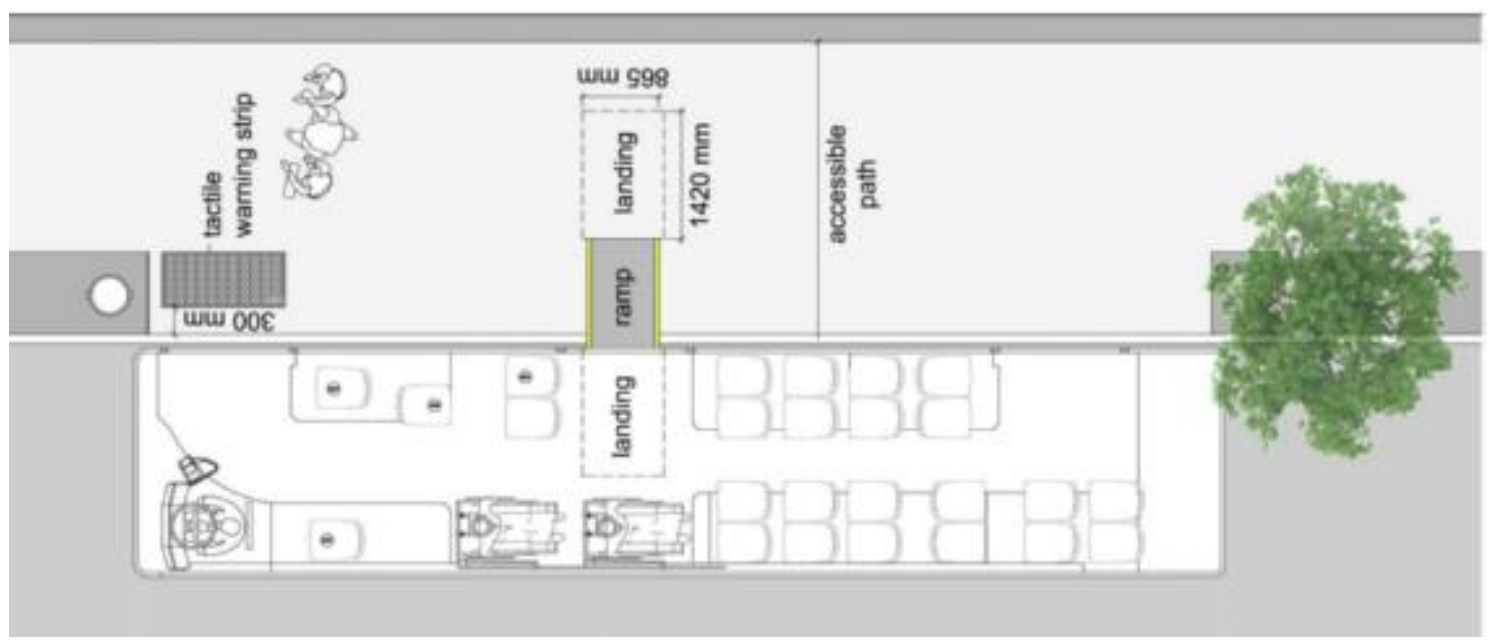

Fonte: Government of Dubai (2017, p.182)

\section{CARACTERÍSTICAS DOS ELEMENTOS DE COMPOSIÇÃO DE PISOS TÁTEIS E/ OU COM DIFERENCIAÇÃO CROMÁTICA}

As principais orientações para sinalização tátil com diferenciação cromática em paragens de autocarro focalizam-se, sobretudo, em aspetos funcionais associados à identificação da paragem de autocarro, à identificação do local de embarque e à marcação do rebordo do lancil (Tabela 2). No Reino Unido faz-se somente alusão a pisos com diferenciação cromática e de textura, pois considera-se que a existência de uma sinalização tátil pode induzir as pessoas com deficiência visual ao erro e provocar acidentes.

As tipologias de composição de piso tátil são geralmente associadas entre si para melhor comunicar às pessoas com dificuldades visuais informações relevantes de uma paragem de autocarro. 
Rev. Interd. em Cult. e Soc. (RICS), São Luís, v. 7, n. 2, p. 241- 260, ago./dez. 2021 ISSN eletrônico: 2447-6498

A sinalização tátil para identificação da paragem de autocarro é feita, geralmente, através de uma linha composta por blocos de piso direcional (nervurado), que se estende transversalmente ao longo do passeio, interceptando o percurso de marcha do pedestre a fim de indicar a presença de um ponto de interesse, nesse caso, uma paragem de autocarro, conduzindo-o diretamente ao ponto de informação e embarque. Esta faixa direcional tem, geralmente, diferenciação cromática e uma largura que varia entre 0,60 a 1,20 m e está distanciada do lancil em 0,50 a 1,00 m. De modo geral, o comprimento da faixa de piso tátil está diretamente associado à variação da largura total do passeio, enquanto a distância do lancil está geralmente associada à presença de outras tipologias de piso tátil: de indicação do local de embarque, da marcação do rebordo do lancil, ou de ambas.

A sinalização tátil para identificação do local de embarque é feita, geralmente, através de piso nervurado ou de alerta (de botão ou liso), localizado no ponto de embarque, que coincide com a porta dianteira do veículo quando estacionado. Na maior parte dos casos, esta tipologia está associada a faixa direcional ou de identificação da paragem de autocarro, descrita anteriormente, e nas suas proximidades situa-se o postalete com informações relevantes acerca das linhas de transporte. Esta faixa tem, geralmente, diferenciação cromática e uma largura/comprimento que varia entre 0,30 a $1,10 \mathrm{~m}$ e está distanciada do lancil entre 0,00 a $1,10 \mathrm{~m}$.

A marcação do rebordo do lancil (de botão ou liso) adverte para a aproximação de um desnível. É instalada paralelamente ao lancil e está associada às paragens de autocarro, paragens elevadas e plataformas de comboios. Esta faixa tem, geralmente, diferenciação cromática (amarelo em Espanha e branco em França) e uma largura que varia entre 0,10 a $0,60 \mathrm{~m}$ e está distanciada do lancil em 0,00 a $0,50 \mathrm{~m}$.

No Reino Unido há especificações em que não se recomenda a utilização de pisos táteis nas paragens e plataformas elevadas (British Standard, 2003), uma vez que uma sinalização equivocada pode induzir as pessoas com deficiência visual ao erro e provocar acidentes. Estudos sobre a mobilidade dos idosos especificam que acham incómodos os pavimentos podotáteis.

Tabela 2: Tipologias de pisos táteis e/ou com diferenciação cromática, por país

\begin{tabular}{|l|c|c|c|c|}
\hline & $\begin{array}{c}\text { Identificação da } \\
\text { paragem de } \\
\text { autocarro }\end{array}$ & $\begin{array}{c}\text { Identificação do local } \\
\text { de embarque }\end{array}$ & $\begin{array}{c}\text { Marcação do } \\
\text { rebordo do lancil }\end{array}$ & $\begin{array}{c}\text { Diferenciação } \\
\text { cromática e de } \\
\text { textura }\end{array}$ \\
\hline Reino Unido & & & + & + \\
\hline Alemanha & + & + & + & + \\
\hline Espanha & + & & + & + \\
\hline
\end{tabular}


Rev. Interd. em Cult. e Soc. (RICS), São Luís, v. 7, n. 2, p. 241- 260, ago./dez. 2021 ISSN eletrônico: 2447-6498

\begin{tabular}{|l|c|c|c|c|}
\hline Bélgica & + & + & & + \\
\hline França & + & + & + & + \\
\hline Brasil & + & + & + & + \\
\hline Dubai & & + & & + \\
\hline
\end{tabular}

Fonte: Elaboração própria

Em alternativa podem-se usar pavimentos macios para aumentar a perceção de todos para a plataforma de espera da paragem de autocarro. É mais comum observar-se a demarcação da área da paragem a partir da diferenciação cromática do piso, como forma de facilitar a sua localização pelo utente.

A utilização de diferenciação cromática entre pavimento tátil e o piso adjacente é, no entanto, uma estratégia comum a todos os países pesquisados, sendo sempre desejável que o percurso pedonal seja destacado visualmente, em termos de cores (Figura 10) e texturas, em relação às demais faixas, para melhor percepção visual.

Figura 10: Recomendação para o contraste cromático do piso tátil no Brasil

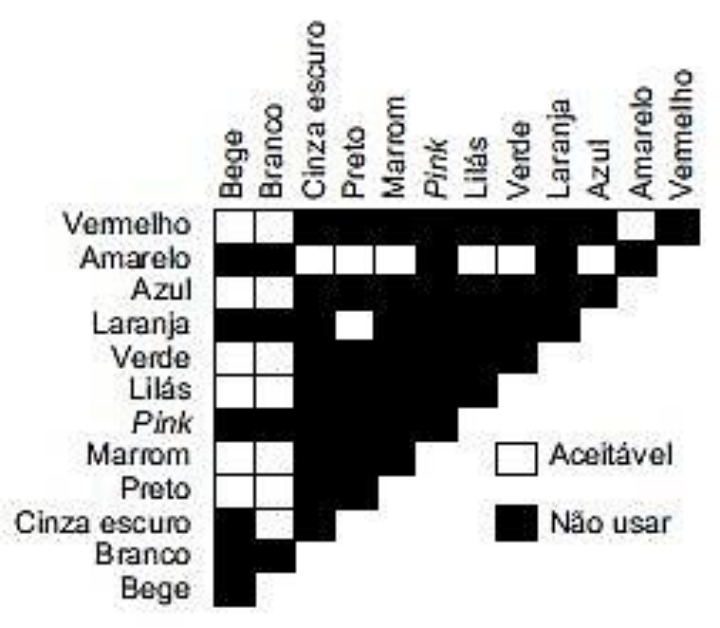

Fonte: ABNT NBR16537 (2016, p.10)

Não obstante terem sido encontrados elementos de sistemas de encaminhamento tátil comuns entre os países pesquisados, as soluções técnicas para a acessibilidade específica de pessoas com deficiência visual em paragens de autocarro, especificamente no que diz respeito à utilização de pisos táteis e/ou com diferenciação cromática, apresenta dissemelhanças sobretudo na composição dos diferentes elementos que os compõem (Figura 11).

Figura 11: Sistemas internacionais de encaminhamento através de piso tátil e/ou com diferenciação cromática em paragens de autocarro 
Rev. Interd. em Cult. e Soc. (RICS), São Luís, v. 7, n. 2, p. 241- 260, ago./dez. 2021 ISSN eletrônico: 2447-6498
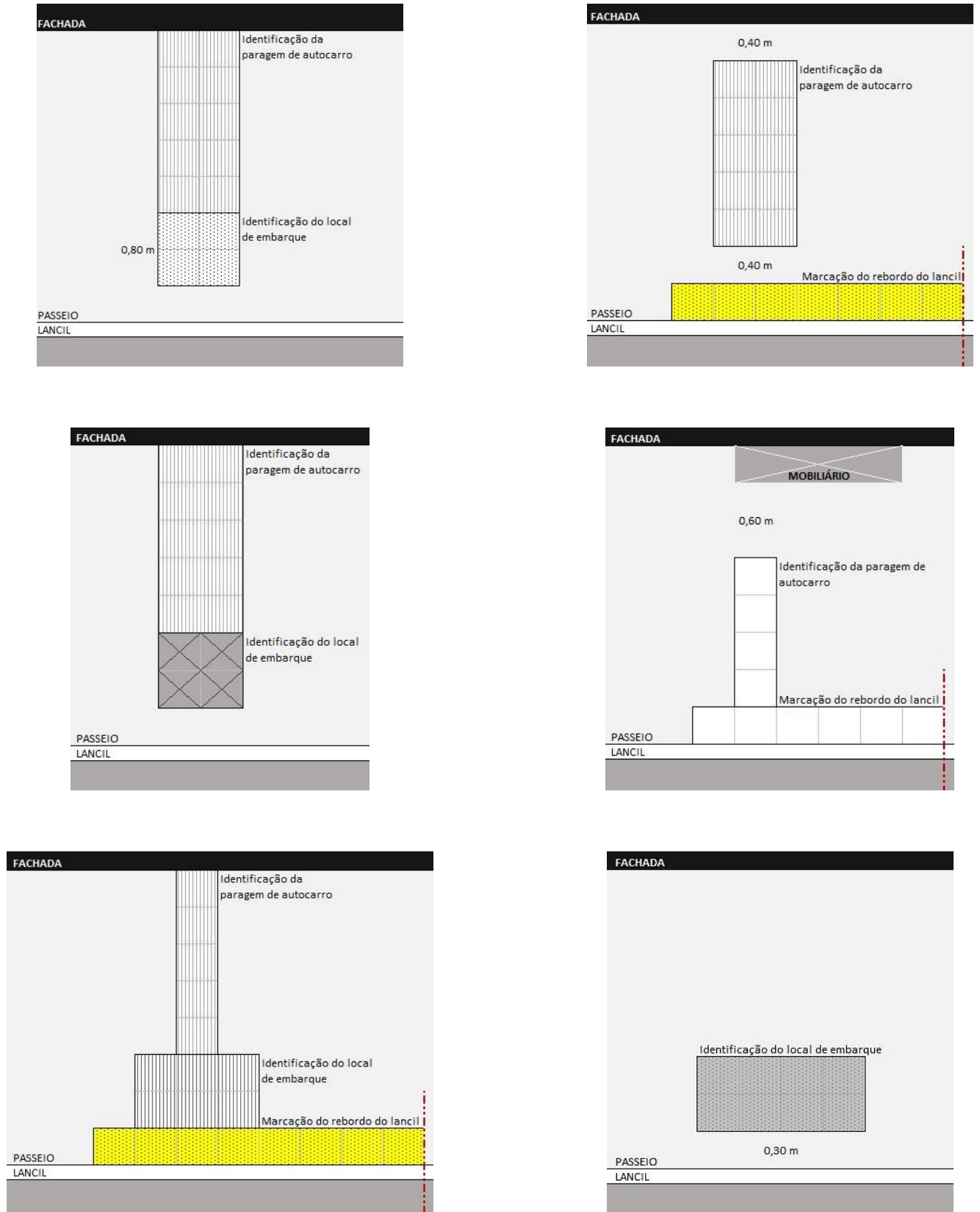

Legenda de tipos de piso
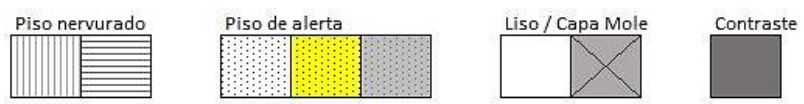

Fonte: Elaboração própria

\section{CONCLUSÃO}

Os países pesquisados apresentam soluções bastante diversas de sistemas de encaminhamento tátil, apesar de utilizarem para isso elementos (placas nervuradas, de botões, 
Rev. Interd. em Cult. e Soc. (RICS), São Luís, v. 7, n. 2, p. 241- 260, ago./dez. 2021 ISSN eletrônico: 2447-6498

lisas, contraste cromático) e linguagens (identificação da paragem de autocarro, identificação do local de embarque, linha de marcação do rebordo do lancil) semelhantes.

Considera-se fundamental a adoção de uma linguagem comum e universal que possa ser utilizada internacionalmente, em todos os contextos do transporte coletivo urbano. A flexibilização para a multiplicidade de soluções táteis desencadeia problemas de reconhecimento por parte das pessoas com deficiência visual, que não conseguem perceber uma unidade nos diferentes relevos e superfícies.

No âmbito do Projecto ACCES4ALL, conclui-se que os pavimentos tácteis não são considerados importantes para as pessoas idosas com mais de 80 anos de idade (Costa Pinto et al. 2020). Do ponto de vista das pessoas com deficiência visual, e da inclusão social, a utilização de pavimentos tácteis é imprescendível, mas também é importante minimizar qualquer impacto adverso ou desconforto para outros utilizadores do espaço público, como é o caso dos cadeirantes e das pessoas idosas.

Actualmente, algumas superfícies que dão informações sobre uma instalação específica são baseadas numa borracha de neoprene ou composto elastomérico semelhante. Estes materiais absorventes de impacto são benéficos para os mais velhos e são considerados como pavimento tátil.

Para conseguir pavimentos alternativos, arquitectos, engenheiros de materiais e designers terão de desenvolver novas investigações e soluções inovadoras para pavimentos táteis, seguindo processos colaborativos que incluem pessoas idosas, participantes com deficiência visual e outros. Estas alternativas devem ser mais cuidadosamente concebidas para promover condições seguras para os peões mais idosos.

O alcance de uma acessibilidade universal passa também pela universalização da linguagem, dos sinais e dos seus significados. Reforça-se, com este trabalho, a necessidade e importância da harmonização de soluções podotáteis no mundo, considerando um contexto de Turismo Acessível.

\section{AGRADECIMENTOS}

O projeto ACCES4ALL - Acessibilidade para Todos no Turismo (SAICT-POL/23700/2016) foi financiado por Fundos Nacionais através da FCT - Fundação para a Ciência e Tecnologia e pelo FEDER, Programas Operacionais CRESC Algarve 2020 e Norte 2020. 
Rev. Interd. em Cult. e Soc. (RICS), São Luís, v. 7, n. 2, p. 241- 260, ago./dez. 2021

ISSN eletrônico: 2447-6498

\section{REFERÊNCIAS}

ABNT - Associação Brasileira de Normas Técnicas ABNT (2004) NBR9050:2004, Acessibilidade a edificações, mobiliário, espaços e equipamentos urbanos.

ACCESIBLE (s/d.) Guia Técnica para la instalación de sistemas de encaminhamento em las infraestructuras de transporte público em la Comunidad de Madrid. Comisión Técnica de Accesibilidad de modos de Transporte. Consejo para la promocion de la accesibilidad y supresion de barreras. Madrid.

ARRÊTÉ du 15 janvier 2007 portant application du décret $n^{\circ}$ 2006-1658 du 21 décembre 2006 relatif aux prescriptions techniques pour l'accessibilité de la voirie et des espaces publics.

British Standard 7997:2003 Products for tactile paving surface indicators - Specification. British Standard. Department of Trade and Industry, Department of Transport, Local Government and the Regions, Royal National Institute for the Blind.

CEREMA (2014) Bandes de guidage au sol - Guide de recommandations. Direction technique Territoires et ville. Centre d'études et d'expertise sur les risques, l'environnement, la mobilité et l'aménagement. Lyon.

CERTU (2003) Recommandations concernant les surfaces tactiles au sol pour personnes aveugles ou malvoyantes. Rapport intermédiaire. Centre d'Etudes sur les Réseaux, les Transports, l'Urbanisme et les constructions publiques.

CERTU (2010) Les cheminements des personnes aveugles et malvoyantes - Recommandations pour les aménagements de voirie. Les point d'arrêt de bus, identification et sécurité de l'aire d'attente. Centre d'Etudes sur les Réseaux, les Transports, l'Urbanisme et les constructions publiques.

COST 322 (1995) Low Floor Buses COST 322, Report EUR 16707 EN, Directorate-General for Transport, European Commission, Luxembourg.

Costa Pinto, P., Assunção, H., Rosa, M.P. (2020) Senior tourists' perceptions of tactile paving at bus stops and in the surrounding environment: Lessons learned from project ACCES4ALL. International Journal of Sustainable Development and Planning, Vol. 15, No. 4, pp. 413-421. https://doi.org/10.18280/ijsdp.150401.

Darcy, S., \& Dickson, T. (2009) A Whole-of-Life Approach to Tourism: The Case for Accessible Tourism Experiences. Journal of Hospitality and Tourism Management, 16(1), 32-44.

DBSV (2016) Bodenindikatoren: Sicherheit und Orientierung im öffentlichen Raum für blinde und sehbehinderte Menschen. Deutscher blinden- und sehbehindertenverband e.v. Berlin.

Department for Transport (2002) Inclusive Mobility - A Guide to Best Practice on Access to Pedestrian and Transport Infrastructure. UK. https://www.gov.uk/government/publications/ inclusivemobility. Acesso em 30/04/2019.

Department for Transport (2007) Guidance on the Use of Tactile Paving Surfaces. Department for Transport, London, UK.

Estratégia Europeia para a Deficiência 2010-2020: Compromisso renovado a favor de uma Europa sem barreiras, COM (2010) 636. 
Rev. Interd. em Cult. e Soc. (RICS), São Luís, v. 7, n. 2, p. 241- 260, ago./dez. 2021 ISSN eletrônico: 2447-6498

Gallez, C. \& Motte-Baumvol, B. (2017) Inclusive Mobility or Inclusive Accessibility? A European Perspective. Cuadernos Europeos de Deusto, 2017, Governing Mobility in Europe: Interdisciplinary Perspectives, 79-104.

GAMAH (2006) Guide de bonnes pratiques pour l'aménagement de cheminements piétons accessibles à tous. Éléments théoriques, Groupe d'action pour une meilleure accessibilité aux personnes handicapées, Les manuels du MET, Région Wallonne, numéro 10 • octobre 2006. http://europe.wallonie.be/sites/default/files/manuel-met-10_1.pdf. Acesso em 23/11/2018.

Government of Dubai (2017) Dubai Universal Design Code. Developed by The Global Alliance on Accessible Technologies and Environments. Dubai.

Howard, David \& Thies, Sibylle \& Nester, Chris \& Maclennan, Hamish \& Kenney, Laurence \& Faruk, Mohamed \& Ormerod, Marcus \& Newton, Rita. (2015) Older people's experiences of using tactile paving. Proceedings of the ICE - Municipal Engineer. 168. 3-10. 10.1680/muen.14.00016.

KOHAUPT, B (2014) Barrierefrei im öffentlichen Raum - Bodenindikatoren. Bietigheim-Bissingen.

Norme NF P 98-351 (février 1989) - Cheminements - Insertion des handicapés - Eveil de vigilance caractéristiques et essais des dispositifs podo-tactiles au sol d'éveil de vigilance à l'usage des personnes aveugles ou malvoyantes.

Ormerod, M.G., Newton, R.A., MacLennan, H.A., Faruk, M, Thies, S. B.A., Kenney, L. P. J., Howard, D. and Nester, C. J. (2015) Older people's experiences of using tactile paving, Municipal Engineer, 168 (1), pp. 3-10.

REAL DECRETO 1544/2007, de 23 de noviembre, por el que se regulan las condiciones básicas de accesibilidad y no discriminación para el acceso y utilización de los modos de transporte para personas con discapacidad. Boletín Oficial del Estado (Número: 290, 04/12/2007, Disposición n 20785, Páginas: 49.948-49.975).

SMT (2009) Guide d'aménagement des quais bus accessibles Schéma Directeur d'Accessibilité, Syndicat Mixte des Transports - SMT Artois Gohelle, Juin 2009.

Transport for London (2006) Accessible bus stop design guidance, London, Mayor of London.

Transport Scotland (2013) Roads for All: Good Practice Guide for Roads, The Scottish Government St Andrews House, Edinburgh, July 2013. 